\title{
Syntactic and Semantic Abilities of Bilingual versus Monolingual Preschoolers with Language Impairment and ADHD
}

\author{
Eliane Ramos \\ Department of Communication Sciences \& Disorders \\ Florida International University \\ Miami, Florida, USA \\ Mildred Suarez \\ Speech Pathology and Educational Center \\ Inc., Miami, Florida, USA \\ Katie Hart \\ Center forChildren and Families \\ DepartmentofPsychology \\ Florida International University \\ Miami, Florida, USA \\ Paulo Graziano \\ Center forChildren and Families \\ DepartmentofPsychology \\ Florida International University \\ Miami, Florida, USA
}

\begin{abstract}
This study examined the semantic and syntactic abilities of monolingual versus bilingual children with concurrent LI and ADHD in English. Sixteen children aged 4 to 7 years of age presenting with concurrent LI and ADHD participated in the study, eight were in the monolingual group and eight in the bilingual group.A story retell task was used to elicit narratives from each participantwhich were then analyzed for various syntactic and semantic productions. No differences were found between the 2 groups in useof grammatical morphology, percentage of mazes produced, and mean length of utterance. The bilingual group had higher rates of complex sentences and lexical diversity, while the monolingual group produced a higher number of utterances per narrative sample.The study concluded that bilingualism presents no disadvantage for children with concurrent LI and ADHD and, in this particular study, indicated an advantage for sentence complexity and vocabulary diversity.
\end{abstract}

Keywords: ADHD, language impairment, bilingual, semantic, syntax, preschool

\section{Introduction}

According to the Diagnostic and Statistical Manual of Mental Disorders (5 ${ }^{\text {th }}$ Edition; DSM-5; American Psychiatric Association, 2013), Attention Deficit-Hyperactivity Disorders (ADHD) are characterized by developmentally inappropriate levels of hyperactivity, impulsivity, and/or inattentive behaviors which may impair daily functioning. ADHD can be classified as either of the inattentive or hyperactivity type, or a combined attention-deficit hyperactivity type, and onset must occur prior to the age of 12. Symptoms must be present for at least 6 months, and it must occur in at least 2 contexts.

In addition to their primary deficits, children with ADHD also show a number of associated difficulties in language development and academic functioning. They are approximately five times more likely to have language delays compared with typically developing children. Various studies have found comorbidity of ADHD and language disorders in approximately 35\% - 50\% of children affected by ADHD and with rates as high as $90 \%$ in studies of clinically referred samples. (Baker \& Cantwell, 1992; Beitchman et al., 2001; Cohen et al., 2000; Jonsdottir et al., 2005; Mueller \& Tomblin, 2012; Tannock\&Schachar, 1996). An area of language difficulty believed to be closely associated with ADHD is that of pragmatics. Pragmatics refers to the appropriate use of social and language skills, which includes timing and the quantity of interaction within a given context (Docking, Munro, Cordier \& Ellis, 2013). 
Many children with ADHD have trouble with turn-taking, topic maintenance, and other pragmatic aspects of language, at times as severe as those observed in children with ASD (Geurts\&Embrechts, 2008; Helland, Birnger, Helland, \& Heimann, 2012; Helland \& Heiman, 2007). In addition, these children's pragmatic deficits include decreased expressive output during spontaneous conversations, and dysfluencies in tasks that require planning and organization of responses (Bruce, Thernland\&Nettelbladt, 2006).

Kim and Kaiser (2000) investigated semantic and syntactic abilities, among other variables, in English speaking monolingual children, 11 children with ADHD and 11 typically developing (TD) children from 6 to 8 years old. The results showed that children with ADHD performed poorer than TD children on sentence imitation and word articulation as measured by the Test of Language Development-2 Primary (TOLD-P2, Newcomer \&Hammil, 1991). Additionally, children with ADHD received significantly lower scores than TD children on the composite measures of spoken language (including picture vocabulary, oral vocabulary, sentence imitation, grammatical understanding, grammatical completion, word discrimination, and word articulation) (Papaeliou C., Maniadaki, K., \& Kakouros, 2015).

Bialystok and colleagues (2016) found that linguistic processing becomes more effortfulin bilinguals, including possible reduction in vocabulary in each language and slower word retrieval. However, bilingualism was also found to enhance aspects of cognitive processing, in particular, executive control. Conversely, Attention-Deficit/Hyperactivity Disorder (ADHD) is associated with a weakened executive control system (Sorge,Toplak \& Bialystok,2016). These two experiences, bilingualism and ADHD, may have similar effects on measures of language proficiency but opposite effects on the executive control system.

Bialystok and colleagues (2016) also conducted a study to investigate the relation between bilingualism and ADHD on language proficiency and executive control in young adults. The groups of participants included either monolingual participants with ADHD (Mon-ADHD), bilingual participants with ADHD (Bil-ADHD), monolingual participants with no reported diagnosis of ADHD (Mon-NoADHD), and bilinguals with no reported diagnosis of ADHD (BilNoADHD). All participants completed tests of language proficiency (vocabulary achievement), ADHD ratings, and executive control. Results of the study indicated that bilingualism had a detrimental effect on vocabulary, as both bilingual groups (ADHD and NoADHD) performed more poorly than both monolingual groups (ADHD and NoADHD). There was no significant difference between the 2 monolingual groups. Surprisingly, there was no difference between any of the groups in one of the executive control tasks (flanker task), but in the other executive control task (stop-signal task), the Bil-ADHD group did worse than all 3 other groups, suggesting that instead of helping participants with ADHD, bilingualism hindered their performance. The authors suggested that this discrepancy may happen because bilingualism may place extra stress in an executive control that is already compromised in ADHD. This study was done on college students and as such included participants that were high achievers in spite of their diagnosis of ADHD. Perhaps these results are not typical of most adults with ADHD and even less so of children with ADHD. To date, we have no comparable study done with children.

In contrast with children with ADHD, children with Specific Language Impairments (SLI) demonstrate deficits in more specific areas of spoken language (i.e., grammatical morphology, syntax, and lexical diversity). Their difficulties may vary due to stages of language acquisition, severity or persistence of impairment (Auza et al., 2018). These difficulties with specific aspects of grammar go beyond a general 2-year delay in language development. As cited in Paradis, Genesee and Crago (2011) these difficulties are specific to vocabulary size, narrative skills, or general grammatical abilities such as sentence length (Leonard, 1998; Rice, 2003). According to Paradis, Genesee and Crago (2011), specific grammatical forms causing them difficulty varies across languages. For example, English-speaking children with SLI have specific problems with the auxiliary verbs and suffixes that indicate the tense of the verb (Rice \&Wexler, 1996). They make errors with the suffix /s/ on the verb go, despite their ability to use similar/s/ sound to make the plural or possessive form.

Although children with SLI are a heterogeneous group, delays in morphosyntactic ability (Rice, 2004) and phonological memory (Dollaghan\& Campbell, 1998) have been associated as clinical markers of SLI. Children with SLI demonstrate delays in syntax characterized by a failure to combine words spontaneously at 18 to 24 months (e.g., Paul, 1996; Rescorla \& Roberts, 2002). Syntactic structures appear to be acquired in roughly the same order as typically developing children, although they make more errors for longer periods of time and use higher rates of ungrammatical sentences (Rescorla \& Roberts, 2002). Children with SLI also show difficulties in learning grammatical morphemes, including certain bound morphemes (plural s, possessive s, past tense -ed, copula be verbs), auxiliary verbs (is, $d o, c a n)$, and small, closed-class morphemes (such as articles $a$ and the). 
In a research forum, Rice (2016) presents an overview of various group comparisons between children with SLI and children with other characteristics or disorders that affect language development, such as bilingualism and ADHD. Regarding bilingualism and SLI, Rice notes that English language learners (ELLs) with SLI acquire English more slowly than they acquire ELLs with typical language development. Further, she also highlights important differences that exist in the linguistic subdomains in ELLs with SLI. More specifically, morphological and nonword repetition abilities are what differentiates the groups the most, morphosyntax errors observed in ELLs are not the same as those observed in ELL children with SLI. Rice also notes that other research by Paradis and colleagues (2011), comparing English- or French speaking children with and without SLI with simultaneous bilingual English and French speaking children with and without SLI, revealed that there is no added disadvantage to learning two languages and that bilingual children with SLI show language skills similar to those of their monolingual peers with SLI.

The literature states that grammatical morphology is often a point of difficulty for both children with language impairment (LI) and bilingual children (Boerma, Wijnen, Leseman, \&Blom, 2017). Children with SLI are characterized by weakness in various language domains, but their deficit in grammatical morphology is particularly prominent (Boerma, Wijnen, Leseman, \&Blom, 2017).

The comorbidity of ADHD and Language Impairment (LI) is widely recognized, but inadequately understood. In an attempt to further investigate whether LI an ADHD represent shared co-occurring disorders, Redmond et al. (2015) compared performances on nonword repetition, sentence recall, and tense marking tasks with children aged seven to nine with LI only, co-occurring ADHD and LI, and TD. The results revealed substantial group effects for the different language measures. In regards to all three tasks, the TD children performed significantly better than the other groups. However, the results did not support ADHD and LI comorbidity as representing interactive disorders or one that involves ADHD as a separate risk factor for children's primary LIs. They found that ADHD had little impact compared to performances of children with SLI, as the results between the two groups were statistically small. Further analyses determined a weak, but positive association between the children's ADHD symptoms and sentence recall tasks.

In summary, research has shown that monolingual children with ADHD perform more poorly than children with typical language development on measures of language (e.g. sentence imitation, word articulation, spoken language measures) (Redmond, 2004). On the other hand, research with bilingual children with ADHD indicate that while they show reduced vocabulary in each of their languages, bilingual children with ADHD show enhanced cognitive processing, especially executive control. Additional research has found no statistical difference between monolingual and bilingual children with ADHD on tasks measuring language and impulse control (Bialystok et al., 2016). Nonetheless, researchers conclude that more comprehensive measures for evaluating all language aspects of children with ADHD continues to be needed. Research with monolingual children with SLI has shown that they have difficulty with specific grammatical forms, but that these differ across languages and that although the children acquire the same language structures as their typically developing peers, the acquisition is delayed, but not deviant. Although research is limited on bilingual children with SLI, particular deficits have been outlined. Bilingual children with SLI demonstrate limitations with later, more demanding structures (i.e., tense, agreement, object clitics, word order in wh- questions, and subordinate clauses) (Hakansson, 2017).

This study attempted to characterize the spontaneous syntactic and semantic English language abilities of bilingual versus monolingual children with concurrent LI and ADHD in a story retell task. We hypothesized that the monolingual group would perform better than the bilingual group in this task.

\section{Methods}

Participants of this study were 16 children with LI and high risk for ADHD divided into 2 groups of 8 children. The monolingual group had 5 males and 3 females and were aged 5 years and 1 month to 6 years and 1 month $($ mean=5;6). The bilingual group had 7 males and 1 female and were aged 4 years and 11 months to 6 years (mean age=5;7). All participants were part of a summer program aimed at improving behavior in children at risk for ADHD. This larger program selected children based on a comprehensive screening battery that included a t-score of 60 and above on any of the Externalizing Composites of the Behavior Assessment System for Children, Second Edition (Reynold \&Kamphaus, 2008; BASC-2), Teacher Report, (Attention Problems, Hyperactivity, and Aggression) and a baseline assessment that included a diagnostic interviewto ascertain the presence of a behavioral disorder and impairment, and parent questionnaires regarding their children's self-regulation skills and behavioral, social, emotional, and academic functioning. Assessment measures of children's intellectual, academic, school readiness and self-regulation skills were also obtained during this initial assessment. (For a complete description of this screening process, see Graziano et al. 2014.) 
Parents were also given the choice of having their children's language skills evaluated. Those who chose to accept the evaluation were scheduled to go to a speech-language clinic where the children were evaluated by masters level speech-language pathology students supervised by certified speech-language pathologists. During the evaluation, parents completed a bilingual questionnaire (Gathercole et al., 2013) while their children were evaluated with the Preschool Language Scale, Fifth Edition (PLS-5, Zimmerman, Steiner \& Pond, 2013). All children scored at least 1 standard deviation below the mean on the PLS-5. Table 1 details all participant demographics including their Total Language Score on the PLS-5, as well as their Auditory Comprehension score (AC) and their Expressive Communication score (EC).

Table 1. Subjects' age, gender, and PLS-5 scores (AC=Auditory Comprehension; EC=Expressive Communication)

\begin{tabular}{|c|c|c|c|c|c|}
\hline \multicolumn{6}{|c|}{ MONOLINGUAL GROUP } \\
\hline SUBJ\# & AGE & GENDER & $\mathrm{AC}$ & $\mathrm{EC}$ & $\begin{array}{l}\text { TOTAL } \\
\text { PLS }\end{array}$ \\
\hline 11 & 5,1 & $\mathrm{M}$ & 73 & 74 & 72 \\
\hline 12 & 5,5 & $\mathrm{~F}$ & 69 & 64 & 64 \\
\hline 13 & 5,1 & $\mathrm{~F}$ & 70 & 78 & 73 \\
\hline 14 & 5,2 & M & 65 & 74 & 68 \\
\hline 15 & 6,1 & M & 75 & 85 & 79 \\
\hline 16 & 5,8 & M & 81 & 68 & 73 \\
\hline 17 & 5,7 & $\mathrm{~F}$ & 83 & 65 & 73 \\
\hline 18 & 5,8 & $\mathrm{M}$ & 96 & 78 & 86 \\
\hline MEANS & 5,6 & & 76.5 & 73.3 & 73.5 \\
\hline \multicolumn{6}{|c|}{ BILINGUAL GROUP } \\
\hline SUBJ\# & AGE & GENDER & $\mathrm{AC}$ & $\mathrm{EC}$ & $\begin{array}{l}\text { TOTAL } \\
\text { PLS }\end{array}$ \\
\hline 21 & 4,11 & $\mathrm{M}$ & 85 & 72 & 77 \\
\hline 22 & 5,7 & $M$ & 83 & 70 & 76 \\
\hline 23 & 5,2 & $\mathrm{M}$ & 80 & 70 & 71 \\
\hline 24 & 5,1 & $\mathrm{M}$ & 72 & 70 & 71 \\
\hline 25 & 7,1 & $\mathrm{~F}$ & 73 & 75 & 73 \\
\hline 26 & 6,0 & $\mathrm{M}$ & 69 & 73 & $69 *$ \\
\hline 27 & 4,10 & $\mathrm{M}$ & 89 & 72 & 77 \\
\hline 28 & 5,9 & $\mathrm{M}$ & 76 & 77 & 77 \\
\hline MEANS & 5,7 & & 78.4 & 72.4 & 74.5714 \\
\hline
\end{tabular}

According to responses to the bilingual questionnaire, all the monolingual children had no formal exposure to Spanish with the exception of 1 child who had inconsistent exposure to Spanish by the maternal grandparents, but the parents reported no use of Spanish by the child. The bilingual group was fairly homogeneous in their exposure to the 2 languages. All of the children were born in the US to bilingual parents who exposed their children to both languages early on, 6 of them from birth, and 2 starting at age 3. All of the children were reported to speak mostly English (from 60 to $100 \%$ of the time) and their current Spanish exposure comes mainly from regular interactions with grandparents.

\subsection{Procedures}

During the summer program, English narrative language samples were collected by having the children retell a story presented to them using a wordless picture book ("Frog, Where Are You" by Mercer Mayer, 1969). The children listened to the story told by the graduate student clinician using a script and then they were asked to go back to the beginning of the book and retell the story while looking at the pictures. Each child's narrative was audio recorded and later transcribed by the graduate clinicians who collected it. Each transcription was then checked by another graduate clinician and any disagreements were resolved by a third reviewer. 
The final transcripts were then coded and analyzed using the Systematic Analysis of Language Transcripts (SALT) software program (Miller\& Iglesias, 2008). Language samples were analyzed for Mean Length of Utterance in morphemes (MLU), Type-Token Ration (TTR), which is a measure of vocabulary diversity that varies from 0 to 1 (proportion of number of different words divided by number of total words), grammatical morpheme usage, mazes (false starts, fillers, repetitions, and revisions), unfinished (abandoned) utterances, and percentage of complex utterances. T-tests were performed to compare results for the bilingual versus monolingual groups.

\section{Results}

Tables 2 and 3 show data from the SALT analysis of language samples obtained during the story retell task from each subject. The columns display the following SALT measures: mean length of utterance, Type Token Ratio, percentage of mazes produced, percentage of abandoned utterances, percentage of complex utterances, number of utterances, and a listing of grammatical morphemes used incorrectly.

Table 2: Monolingual Group SALT Analysis Data

\begin{tabular}{|l|l|l|l|l|l|l|l|}
\hline \multicolumn{7}{|l|}{ Monolingual } \\
\hline NUMBER & CHILD MLU & $\begin{array}{l}\text { CHILD } \\
\text { TTR }\end{array}$ & \%MAZE & $\begin{array}{l}\text { ABAND } \\
\text { UTT }\end{array}$ & MORPH & \% COMPLEX & \# UTT \\
\hline 1 & 6.12 & 0.2 & 69 & 15 & ed; 's; 3s ir past & 8.99 & 89 \\
\hline 2 & 4.66 & 0.33 & 38 & 20 & ed; ir past & 1.98 & 101 \\
\hline 3 & 5.32 & 0.37 & 69 & 35 & NO ir past & 5.88 & 102 \\
\hline 4 & 5.25 & 0.37 & 57 & 22 & ed; ir past & 12.50 & 72 \\
\hline 5 & 6.8 & 0.42 & 75 & 1 & NO & 24.56 & 57 \\
\hline 6 & 3.95 & 0.38 & 32 & 18 & ed.'s; ir past & 1.28 & 78 \\
\hline 7 & 7.68 & 0.32 & 58 & 3 & 3 s & 12.90 & 62 \\
\hline 8 & 7.88 & 0.44 & 64 & 3 & NO & 14.29 & 28 \\
\hline MEANS & 5.96 & 0.35 & 57.75 & 14.63 & & 10.30 & 73 \\
\hline
\end{tabular}

Table :3 Bilingual Group SALT Analysis Data

\begin{tabular}{|l|l|l|l|l|l|l|l|}
\hline \multicolumn{2}{|l|}{ Bilingual } \\
\hline NUMBER & $\begin{array}{l}\text { CHILD } \\
\text { MLU }\end{array}$ & $\begin{array}{l}\text { CHILD } \\
\text { TTR }\end{array}$ & \%MAZE & ABAND UTT & MORPH & $\begin{array}{l}\text { \% } \\
\text { COMPLEX }\end{array}$ & \# UTT \\
\hline 1 & 5.32 & 0.41 & 31 & 15.7 & $3 \mathrm{~s}$ & 3.70 & 54 \\
\hline 2 & 6.25 & 0.34 & 81 & 1 & NO & 11.90 & 42 \\
\hline 3 & 8.29 & 0.38 & 47 & 6 & NO-IR Past & 30.00 & 30 \\
\hline 4 & 5.67 & 0.59 & 28 & & NO-IR Past & 19.44 & 36 \\
\hline 5 & 7.74 & 0.32 & 38 & 4 & NO-IR Past & 23.08 & 39 \\
\hline 6 & 7.59 & 0.4 & 36 & 4 & NO-IR Past & 26.67 & 45 \\
\hline 7 & 5.80 & 0.45 & 68 & 7 & 3s & 10.53 & 38 \\
\hline 8 & 6.31 & 0.61 & 74 & 12 & NO-IR PAST & 18.52 & 27 \\
\hline MEANS & 6.62 & 0.44 & 50.38 & 7.1 & & 17.98 & 38 \\
\hline
\end{tabular}

T-tests were performed to compare monolingual and bilingual subjects' usage of syntax and semantics. Analysis of the measures revealed the groups' results were mixed in both syntactic and semantic measures. For the bilingual group, the results demonstrated significantly higher percentage of complex utterances $(t=-1.86 . p<.05)$ and significantly higher Type Token Ratio $(\mathrm{t}=-1.80, \mathrm{p}<.05)$ compared to the monolingual group. For the monolingual group, the results demonstrated significantly higher number of utterances $(\mathrm{t}=3.74, \mathrm{p}<.05)$ compared to the bilingual group. Results also revealed no differences in use of grammatical morphology, percentage of mazes produced $(t=0.80, p=0.2)$ and mean length of utterance $(\mathrm{t}=-1.04, \mathrm{p}=0.15)$, between the groups.

\section{Discussion}

As studies have shown, children with ADHD display a considerable amount of language difficulties. These difficulties include but are not limited to: mazes, false starts, fillers, revisions, and repetitions. After gathering language samples from monolingual and bilingual children with ADHD (ages 4 to 7), the results confirmed that the children with ADHD and LI did have difficulties in all these areas. 
Following the analyses of syntactic measures, the results revealed no significant differences in: grammatical morphology, percentage of mazes produced, and mean length of utterance. As previously stated by researchers Boerma, Wijnen, Leseman, \&Blom (2017) grammatical morphology is often a point of difficulty for both children with language impairment and bilingual children. Our findings show that both monolingual and bilingual children demonstrated no difference in their use of grammatical morphology. Nonetheless, it was noted that both groups had difficulties in the production of irregular past tense. Our results indicated that even though MLU was low for both groups, there wasno significant difference between the two groups, thus indicating that MLU was not affected by monolingual or bilingual status.

On the other hand, our analyses did reveal significant differences in: percentage of complex sentences, Type Token Ratio (TTR), and number of utterances produced. It was surprising to find that there was a significant difference in the complexity of their sentences given that we did not find a significant difference in the MLU between the two groups. A higher TTR in the bilingual group was noted compared to the monolingual group. It is possible that a higher TTRin the bilingual group will be due to their exposure to the vocabularies of two language systems. Lastly, the monolingual group was found to have a higher number of utterances when compared to their bilingual counterparts.Perhaps this is because monolinguals may have a higher level of confidence in their use of the English language. Even though percentage of mazes was quite high for both groups, which is expected in children with ADHD, there was no difference between the two groups.

\section{Conclusion}

Monolingual and bilingual 4 to 7-year-oldchildren with ADHD demonstrated similar results when syntactic and semantic tasks were examined. The results of the present study indicated that bilingual children were not at a disadvantage as we had predicted.Bilingual participants demonstrated better performance on certain measures. These included a higher percentage of complex utterances as well as higher TTR, when compared to monolingual participants.Perhaps extraneous variables that we were not able to control for, such as differences in SES between the groups, could have had an impact on the results. It is also possible that the small sample size of this study impacted its results. Future studies should include more subjects. The inclusion of control groups such as monolingual and bilingual children with SLI and no ADHD as well as children with ADHD and no SLI would also allow for comparisons that are more thorough.

\section{Acknowledgements}

The research reported here was supported by the Institute of Education Sciences, U.S. Department of Education, through Grant R324A120136 as well as a local grant from The Children's Trust (1329-7290) to the last author. The opinions expressed are those of the authors and do not represent views of the Institute or the U.S. Department of Education or The Children's Trust. We would also like to acknowledge the support of Miami-Dade County Public Schools and thank the families and dedicated staff who participated in the study.

\section{References}

American Psychiatric Association. (2013). Diagnostic and statistical manual of mental disorders (5th ed.). Washington, DC: Author.

Auza B., A., Harmon, M. T., \& Murata, C. (2018). Retelling stories: Grammatical and lexical measures for identifying monolingual spanish speaking children with specific language impairment (SLI). Journal of Communication Disorders, 7152-60. doi:10.1016/j.jcomdis.2017.12.001

Baker, L., \& Cantwell, D. P. (1992). The association between emotional/behavioral disorders and learning disorders in children with speech/ language disorders. Advances in Learning and Behavioral Disabilities, 6, 27-46.

Beitchman, J., Adlaf, E., Douglas, L., Atkinson, L., Young, A., Johnson, C., Escobar, M., \& Wilson, B. (2001). Comorbidity of psychiatric and substance use disorders in late adolescence: a cluster analytic approach. American Journal of Drug and Alcohol Abuse, 27, 421-440.

Bialystok, E., Hawrylewicz, K., Wiseheart, M., \&Toplak, M. (2016). Interaction of bilingualism and AttentionDeficit/Hyperactivity Disorder in young adults. Bilingualism: Language and Cognition,20(03), 588-601. doi:10.1017/s1366728915000887

Boerma, T., Wijnen, F., Leseman, P., \&Blom, E. (2017). Grammatical Morphology in Monolingual and Bilingual Children With and Without Language Impairment: The Case of Dutch Plurals and Past Participles. Journal of Speech Language and Hearing Research, 60(7), 2064. doi:10.1044/2017_jslhr-1-16-0351 
Bruce, B., Thernlund, G., \&Nettelbladt, U. (2006). ADHD and language impairment. European Child \& Adolescent Psychiatry, 15(1), 52-60. doi:10.1007/s00787-006-0508-9

Cohen, N. J., Vallance, D. D., Barwick, M., IM, N., Menna, R., Horodezky, N. B. and Isaacson, L. (2000). The interface between ADHD and language impairment: An examination of language, achievement, and cognitive processing. Journal of Child Psychology and Psychiatry, 41, 353-362.

Docking, K., Munro, N., Cordier, R., \& Ellis, P. (2013). Examining the language skills of children with ADHD following a play-based intervention. Child Language Teaching \& Therapy, 29(3), 291-304.

doi:10.1177/0265659012469042

Dollaghan, C., \& Campbell, T. (1998). Nonword repetition and child language impairment. Journal of Speech, Language, and Hearing Research, 41, 1136-1146.

Gathercole, V.C.M., Thomas, E.M., Roberts, E.J., Hughes, C.O., \& Hughes, E.K. (2013).Why assessment needs to take exposure into account: Vocabulary andgrammatical abilities in bilingual children. In VCM Gathercole (ed.), Issues in theassessment of bilinguals. Bristol: Multilingual Matters. 20-55.

Geurts, H. \&Embrechts, M. (2008). Language Profiles in ASD, SLI, and ADHD. Journal of Autismand Developmental Disorders, 38, 1931-1943.

Graziano, P., Slavec, J., Hart, K., Garcia, A., \& Pelham, W. (2014). Improving school readiness in preschoolers with behavior problems: Results from a summer treatment program. Journal of Psychopathology and Behavioral Assessment, 36(4), 555-569.

Hakansson, G. (2017). Typological and developmental considerations on specific language impairment in monolingual and bilingual children: A Processability Theory account. Language Acquisition, 24(3), 265-280.

Helland, W., \&Heimann, M. (2007). Assessment of pragmatic language impairment in children referred to psychiatric services: a pilot study of the Children's communication Checklist in a Norwegian Sample. Logopedics Phoniatrics Vocology, 32, 23-30.

Helland, W., Biringer, E., Helland, T., \&Heimann, M. (2012). Exploring Language profiles for children with ADHD and children with Asperger Syndrome. Journal of attention Disorders, 16, 34-43.

Jonsdottir, S., Bouma, A., Sergeant, J. A., \&Scherder, E. J. A. (2005). The impact of specific language impairment on working memory in children with ADHD combined subtype. Archives of Clinical Neuropsychology, 20, 443456.

Kim, O. H., \& Kaiser, A. P. (2000). Language characteristics of children with ADHD. Communication Disorders Quarterly, 21, 154-165.

Leonard, L. (1998). Children with specific language impairment. Cambridge, MA: The MIT Press.

Mayer, M. (1969). Frog, where are you? New York, NY: Dial Press.

Miller, J. F., \& Iglesias, A. (2008). Systematic Analysis of Language Transcripts (SALT), English \& Spanish (Version 9) [Computer software]. Madison: University of Wisconsin Madison, Waisman Center, Language Analysis Laboratory.

Mueller, K., \& Tomblin, B. (2012). Examining the comorbidity of language impairment and ADHD. Topics in Language Disorders, 32(3), 228-246.

Newcomer, Phyllis L., \& Donald D. Hammill. (1991). Test of Language Development-Primary: Second Edition, ProEd.

Papaeliou, C., Maniadaki, K., \&Kakouros, E. (2015). Association Between Story Recall and Other Language Abilities in Schoolchildren with ADHD. Journal of Attention Disorder, 19, 53-62.

Paradis, J., Genesee, F., \&Crago, M. (2011) Dual language development and disorders: A handbook on bilingualism and second language learning $2^{\text {nd }}$ Edition. Baltimore, Maryland: Paul H. Brookes Publishing Company.

Paul, R. (1996). Clinical implications of the natural history of slow expressive language development. American Journal of Speech-Language Pathology, 5, 5-21.

Redmond, S. M. (2004). Conversational Profiles of Children with ADHD, SLI and Typical Development. Clinical Linguistics \& Phonetics, 18, 107-125.

Redmond, S.M., Ash, A.C. \&Hoganb, T.P. (2015). Consequences of Co-Occurring Attention-Deficit/Hyperactivity Disorder on Children's Language Impairments. Language, Speech, and Hearing Services in Schools, 1-13.

Rescorla, L., \& Roberts, J. (2002). Nominal versus verbal morpheme use in late talkers at ages 3 and 4. Journal of Speech, Language and Hearing Research, 45, 1219-1232.

Reynolds, C. R., \&Kamphaus, R. W. (2008). Behavior assessment system for children - second edition (BASC-2) intervention guide for emotional and behavioral problems. Bloomington, MN: Pearson.

Rice, M. (2004). Growth models of developmental language disorders. In M. L. Rice \& S. F. Warren (Eds.), Developmental language disorders: From phenotypes to etiologies (pp. 207-240). Mahwah, NJ: Erlbaum. 
Rice, M. (2016). Specific Language Impairment, Nonverbal IQ, Attention-Deficit/Hyperactivity Disorder, Autism Spectrum Disorder, Cochlear Implants, Bilingualism, and Dialectal Variants: Defining the Boundaries, Clarifying Clinical Conditions, and Sorting Out Causes. Journal of Speech, Language, and Hearing Research, $59,122-132$.

Rice, M. L., (2003). A unified model of specific and general language delay: Grammatical tense as a clinical marker of unexpected variation. In Y. Levy \& J. Schaeffer (Eds.), Language competence across populations: Towards a definition of specific language impairment (pp. 63-94). Mahwah, NJ: Lawrence Erlbaum Associates.

Rice, M. L., \& Wexler, K. (1996). Toward tense as a clinical marker of specific language impairment in English speaking children. Journal of Speech and Hearing Research, 39, 1239-1257.

Sorge, G. B., Toplak, M. E., \& Bialystok, E. (2016). Interactions between levels of attention ability and levels of bilingualism in children's executive functioning. Developmental science, 20(1), 10.1111/desc.12408.

Tannock, R., \&Schachar, R. (1996). Executive dysfunction as an underlying mechanism of behavior and language problems in attention deficit hyperactivity disorder. In J.H. Beitchman, N.J. Cohn, M.M. Konstantareas, \& R. Tannock (Eds.), Language, learning, and behavior disorders: developmental, biological, and clinical perspectives (pp. 128-155). Cambridge: Cambridge University Press.

Zimmerman, I.E., Steiner, V.G., \& Pond, R.E. (2013). Preschool Language Scales, Fifth Edition (PLS-5). San Antonio, TX: The Psychological Corporation. 